\title{
A comparison of skills competency test scores among Philippine-educated nursing students after an intensive medical-surgical course
}

\author{
Margaret Fink * Debbie Daunt, Patricia R. Harris, Barbara McCamish \\ Dominican University, San Rafael, CA, United States
}

Received: May 4, 2015

DOI: $10.5430 /$ jnep.v5n $11 \mathrm{p} 42$
Accepted: July 29, 2015

Online Published: August 17, 2015

URL: http://dx.doi.org/10.5430/jnep.v5n11p42

\begin{abstract}
Objective: This study examined the effect of a 10-week intensive medical-surgical course on ability to perform 16 common, acute care skills among Philippine educated nursing students seeking licensure in California. The aims of the study were to (1) determine competency in performing skills at the start of the medical-surgical course and (2) evaluate the effectiveness of the medical-surgical course in improving skill competency.

Methods: Twenty-three Philippine educated nursing students participated in a 4-hour skills competency test procedure that involved 4 patient care stations and 16 common acute care skills. During the last week of the 10-week medical-surgical course that included 24 open simulation lab practice hours, these same 23 students repeated the testing procedure.

Results: At the start of the course skill competency scores were low with many of the participants unable to complete the skills stations. A significant improvement occurred in scores for 14 of the 16 skills when tested in the final week of the medical-surgical nursing course under the same conditions $(p<.05)$.

Conclusions: Conducting the nursing skills competency testing procedure at the start of the course informed faculty about the abilities of Philippine educated nursing student participants. Because of potential differences in nursing education abroad, graduates of nursing programs in the Philippines might benefit from competency testing to evaluate initial skill levels, followed by intensive review of commonly performed nursing skills in the United States, if warranted by initial results.
\end{abstract}

Key Words: Internationally educated nurses, Philippine educated nursing students, Skills competency testing, Board of registered nursing

\section{INTRODUCTION}

\subsection{Background}

The United States (US) will soon face the largest shortage of registered nurses (RNs) to date. The American Association of Colleges of Nursing (AACN) projects the total number of RN job openings in the US will reach 1.2 million by the year 2022, which is double the size of any shortage since the 1960s. ${ }^{[1]}$ According to the Bureau of Labor Statistics, the demand for nurses is expected to grow by $19 \%$ in the United States (US). ${ }^{[2]}$ In California (CA), 100,000 nurses will be needed by the year 2030 primarily due to the burgeoning older population in urban areas and fewer available nurses in rural areas. ${ }^{[3]}$

The literature reports several reasons for this growing nursing shortage including demographic changes, current RNs aging out of the profession, and increased access to healthcare for

*Correspondence: Margaret Fink; Email: margaret.fink@dominican.edu; Address: Dominican University, San Rafael, CA, United States. 
all. $^{[1,2]}$ The demand for RNs is destined to outpace US capacity to fill vacancies due to nursing faculty shortages and lack of space in academic programs. ${ }^{[2]}$

Previous nursing shortages have led to reliance upon nurses educated outside of the US. ${ }^{[4]}$ In 2007, for example, over 22,000 internationally educated nurses (IENs) passed the National Council Licensure Examination-Registered Nurse (NCLEX), representing 12\% of the successful examinees and a substantial number of new RNs entering the labor force. ${ }^{[5]}$ According to $\mathrm{Xu}$, Zaikina-Montgomery, and Shen, ${ }^{[6]}$ IENs are playing an increasingly significant role in the care of older adults. With the demographic shift toward an older population in the US, reliance on IENs is projected to increase.

The designation of IEN refers to nurses who were born and educated in nursing programs outside of the US, or to those who were born in the US, but traveled abroad to earn a nursing degree. ${ }^{[7]}$ Global migration of nurses can be traced to the 1960s when immigration laws were revised and many traveled to the US with work visas. ${ }^{[8,9]}$ The Philippines remains the worldwide leader in creating nurses for the international market. ${ }^{[10]}$ Nurses who were educated in the Philippines often make the state of CA their new home. As of 2010, $24 \%$ of nurses practicing in CA were educated outside of the $\mathrm{US}^{[11]}$ with $20 \%$ being from the Philippines. ${ }^{[12]}$ Because of the high need and number of IENs pursuing RN licensure and work in the US, and the lack of information about preparedness to practice in the US, more research regarding the qualifications and skills of IENs would be beneficial.

Many IENs have been impacted by the CA Board of Registered Nursing (BRN) regulation 1426(d), which states theory and clinical experience must be completed concurrently. ${ }^{[13,14]}$ IENs who arrive in the state of CA and pursue $\mathrm{RN}$ licensure might now receive a letter denying licensure until completion of courses in medical-surgical, maternalnewborn, psychiatric-mental health, and/or pediatric courses which meet this requirement.

During the summer of 2014, the Office of Admissions at a university in Northern CA maintained a waiting list of IENs that numbered in the hundreds. IENs on the waiting list had received letters from the BRN stating a deficiency, and a requirement to repeat one or more nursing courses. These IENs had attained nursing degrees in countries such as Nepal, Algeria, Romania, and the Philippines. The majority of IENs on this list had attained BSN degrees in the Philippines, and had received letters requiring completion of BRN approved medical-surgical and maternal-newborn nursing courses. Based on this need, faculty at the university established both a medical-surgical and psychiatric nursing course for the summer of 2014. The faculty were not able to establish a maternal-newborn course due to lack of clinical sites. While the psychiatric nursing course included students from a variety of countries around the world, the medicalsurgical course consisted exclusively of Philippine educated nursing students (PENSs). Each of the 23 PENSs in the medical-surgical course had received a bachelor of science in nursing (BSN) from the Philippines within the last decade.

Navigating into unchartered territory with little background on the PENSs' prior educational experience outside of the US, faculty were concerned about performance in wellestablished clinical settings. Therefore, the lead faculty for the IEN medical-surgical course developed and implemented a skills competency testing program to establish a baseline, and facilitate a safe and effective clinical experience.

\subsection{Review of the literature}

There is little in the literature that compares international nursing education with US nursing education. Differences may be implied based upon authors who have studied IENs, and report struggles with expectations of $\mathrm{RN}$ autonomy in the nursing role, new technologies, and individual nursing care versus team based nursing care. Much has been written about the difficulties of nurses transitioning to work in the US. ${ }^{[15-21]}$

Upon arrival to the United States, IENs are faced with difficulties in acclimating to a new culture and transitioning to a different healthcare setting. Newton, Pillay, and Higginbottom $^{[18]}$ conducted a comprehensive review of the literature to learn about the reasons for and challenges with immigration among nurses. From this literature, five themes were extracted: challenges, cultural displacement, deskilling, discrimination, and strategies to smooth transition. They concluded that IENs experience unique challenges to entering the US workforce and that strategies are necessary to reduce transition difficulties.

Singh and Sochan ${ }^{[16]}$ interviewed 12 IENs who struggled to become RNs in Canada. These RNs came from the Philippines, China, India, and Ukraine. Three themes emerged: hope of becoming RN, disillusionment, and navigating the disillusionment. The participants alluded that the credentialing process needs more transparency and coordination prior to and on arrival to the destination country. In a similar study, Jose ${ }^{[15]}$ found six themes emerged from the interviews of 20 IENs who had migrated to the US including dreams of a better life, a difficult journey, a shocking reality, rising above the challenges, feeling and doing better, and readiness to help others. IENs were surprised that families in the US did not take care of the patients. They reported struggling 
with technology and the high level of autonomy of US RNs. According to the interviewed IENs, media in their countries frequently show the ease of migrating to developed countries, which was not the reality they experienced. ${ }^{[15]}$

Wheeler, Foster, and Hepburn ${ }^{[17]}$ conducted interviews to compare work experiences between US nurses and IENs. All had practiced for at least one year in the US and the majority had migrated after 1990. Compared to their US counterparts, IENs faced additional barriers including difficulty in establishing patient care relationships due to a foreign accent. Most IENs were also overwhelmed by having to provide total patient care having been accustomed to team nursing in which several nurses each have a specific responsibility in caring for a patient. IENs also perceived that nurses in the US were treated with less respect by patients and their families. ${ }^{[17]}$

Several medical centers have sought to redress immigration challenges by providing orientation programs to bridge the gap between previous practice in the country of origin and the destination country. ${ }^{[7,19]}$ Vestal and Kautz ${ }^{[19]}$ interviewed a focus group of new PENs at a North Carolina medical center to assess the effectiveness of their orientation program. A dedicated Filipino staff development instructor served as a liaison for the new PENs providing assistance with housing, childcare and resources to pass the state board exam. Participants in the focus group reported that differences existed in technology, such as automatic blood pressure cuffs, and in the need to provide personal care in the US hospital. The PENs felt that they had to prove themselves and that some patients underestimated their abilities. Participants valued the organization's efforts to assist them to acculturate. ${ }^{[19]}$

Adeniran et al. ${ }^{[7]}$ described a program called "Transitioning Internationally Educated Nurses for Success," developed at a Pennsylvania medical center to ease the IENs' transition into the US healthcare system. Three concerns were identified for IENs who arrived to the US. These included a difference in nursing practice style, communication differences, and cultural differences. Li-Chen ${ }^{[17]}$ added to these findings through a study that involved interviewing Filipina nurses on their experiences transitioning to US hospitals. Participants in Li-Chen's study had challenges with communication, cultural dissonance, independent decision-making, and role uncertainty.

According to statistics from the World Health Organization, ${ }^{[22]}$ healthcare differences are evident between the Philippines and the US. For example, the average life expectancy in the US is at least 10 years longer than that in the Philippines. Money spent per capita on healthcare is about four times higher in the US. And there are 61 nurses per 10,000 in the
Philippines compared with 94 in the US. With such striking differences between the two countries' populations, fiscal resources, disease burdens, and healthcare workforce, more work is needed to bridge the international gap.

\subsection{Purpose of the study}

The purpose of this study was to (1) investigate PENSs' baseline competency in performing 16 common medical-surgical skills, and (2) measure competency in the 16 skills at the end of a 10-week intensive medical surgical nursing course that included practice in the Clinical Simulation Center, along with clinical and classroom hours. Skill competency was measured at the beginning of the course and then repeated during the last week of the course after students had completed 24 hours of practice in the Clinical Simulation Center on campus.

\subsection{Research question}

What is the difference in PENSs' scores for 16 medicalsurgical skills performed at the beginning versus at the end of a 10-week summer medical-surgical nursing course that includes practice in a clinical simulation center, inpatient clinical hours, and didactic class meetings?

\section{METHOD}

\subsection{Ethics}

This study was approved by the University's Institutional Review Board for the Protection of Human Subjects. All PENSs in the summer medical-surgical nursing course were required to participate in skills competency testing in the first week and the last week of the course. All PENSs were invited to participate in the study by agreeing to have their scores included as part of the study. They were informed that participation status would not affect their success in the course. PENSs indicated their willingness to have their data included in this study by signing a consent form. The lead instructor, who was also an author in this study, turned the pre and posttest scores over to the co-authors for data entry and analysis. Data was entered into SPSS ${ }^{[23]}$ with each student given an assigned number to maintain anonymity. To minimize bias, the author who conducted the data entry and statistical analyses was blinded to participant identity.

\section{Procedures}

This study involved a quasi-experimental pre- and post-test design using a convenience sample of students enrolled in a medical-surgical nursing course designed for internationally educated nurses. The study took place at an independent, non-profit, 4-year university in the San Francisco Bay Area. The medical-surgical course was initially comprised of 24 students. One student left the course shortly after it started 
and was not included in the final sample of 23 participants. While the course was designed for any IEN who needed to complete medical-surgical nursing, only students from the Philippines needed the class.

The 10-week medical-surgical course involved three components: classroom theory/lecture with written tests, acute care clinical at a local community hospital caring for patients on medical, surgical and cardiac units, and 24 hours of practice in the Clinical Simulation Center on the university campus. The theory/classroom portion of the course was assigned a letter grade while the clinical portion was assigned a pass or fail grade. The skills competency testing scores were not counted as part of the course grade; however, if students scored under 77 points at the end of the course, they would have to repeat the test until they achieved the passing score.

Prior to the start of the medical-surgical nursing course, PENSs came to the University for an orientation of the Clinical Simulation Center. The orientation included an introduction to the academic electronic health record system, Simchart (Elsevier, St Louis), review of the medical records of the four patients who were to be used in the testing process, and introduction to the four low fidelity manikins that represented the four patients as listed below.

PENSs began their participation in the study on the following day, having no preparation for the pre-test other than orientation the day before. They arrived to the on-campus Clinical Simulation Center with only the knowledge that they would be tested on skills performance at four patient care stations with each station requiring completion of four skills (16 skills total). Test monitors were recruited from a pool of traditional BSN students who were ready to graduate at the University. Each test monitor was familiar with the skills station from previous classes. Test monitors were paid a student worker wage. A test monitor was present at each of the four stations to observe and score the PENSs using the author created scoring rubrics. The monitor provided a hand-off report as the PENSs arrived at each station. The monitor also served as an inquisitive family member and assistant for the skills as needed.

The skills competency testing stations were as follows:

(1) Irene Banaag: 78-year-old woman from the Philippines with end stage colon cancer. Needed Salem sump nasogastric tube insertion, peripherally inserted central catheter (PICC) blood draw, PICC dressing change, and subcutaneous heparin injection.

(2) Guadelupe Diego: 56-year-old woman from Mexico who had a stroke 2 days ago and developed aspiration pneumonia. Needed indwelling urinary catheter insertion, saline lock insertion, enteral feeding set up, and 2 subcutaneous insulin injections (glargine and lispro).

(3) Donald Dunlap: 48-year-old African American man with high body mass index who underwent ventral hernia repair 2 days ago. Needed primary intravenous fluid, intravenous piggy back medication of cefazolin, wet to moist dressing change, and medication administration by intravenous push.

(4) Harley Hogg: 48-year-old Caucasian man with multiple traumas from motorcycle accident. Sustained pneumothorax and airway obstruction. Has history of alcoholism and liver failure. Needed tracheostomy suctioning, chest drain set up, packed red blood cell transfusion, and subcutaneous vitamin $\mathrm{K}$ injection.

Over the course of eight weeks, in between pre and posttesting, PENSs were required to complete a minimum of 24 hours of practice on the 16 assigned skills. Practice sessions began with demonstrations from two faculty members. PENSs then proceeded through open hours rotating through the stations, following the steps on the score sheets. The lead faculty member was present to offer guidance and feedback throughout every practice session. In the last week of the medical-surgical course, post-testing was conducted. The same PENSs rotated through the same four stations in an assigned 4-hour time period. Again, senior students served as test monitors sitting at the bedside, using the same author created score-sheets to assign scores.

\section{Outline of procedure}

- Early June 2014 - orientation to the Clinical Simulation Center

- Early June 2014 - first week of class, pretesting of each student at 4 skills stations performing 4 skills at each station with paid test monitor scoring each student

- Early June 2014-Late July 2014- open lab practice with demonstration and feedback provided by faculty $=24$ hours

- Late July 2014- last week of class, post-testing of each student at 4 skills stations performing 4 skills at each station with paid test monitor scoring each student

\subsection{Instrument}

The skill competency test scoring rubrics were developed by the researchers using a table template and a variety of wellknown skills manuals, such as "Clinical Nursing Skills and Techniques 8th edition". [24] The template included Quality and Safety Education for Nurses (QSEN) competencies ${ }^{[25]}$ and essential elements of every skill were organized by steps of the nursing process. The template contained spaces to document numerical scores that ranged from 0 to 100 . The skill 
competency test scoring instrument had been used approximately 500 times in the past 2 years to test the University's traditional BSN students, but had not been used with IEN students prior to this study.

\subsection{Data analysis}

Scores on the pre- and post-tests were compared using nonparametric statistics to minimize the influence of outliers.

\section{Results}

Table 1 represents demographic data of the participants. The sample was predominantly women with an average age of 28 years. The majority had licensed vocational nurse (LVN) licenses $(55 \%)$ and many worked in a caregiving capacity. Most of the participants had received BSN degrees in the last 3 years; however, there were two in the sample who had graduated as long ago as the year 2005 .

Table 1. Participant demographics

\begin{tabular}{|c|c|}
\hline Attribute & Statistical data \\
\hline \multirow{4}{*}{ Age $(n=23)$} & Mean $=28 \pm 7$ years \\
\hline & Median $=25$ years \\
\hline & Range $=21$ to 48 years \\
\hline & Mode $=22$ years \\
\hline \multirow{2}{*}{ Gender $(n=20)$} & Female $=14(70 \%)$ \\
\hline & Male $=6(30 \%)$ \\
\hline \multirow{2}{*}{ Year received BSN degree $(n=23)$} & Range $=2005-2013$ \\
\hline & Mode $=2012$ \\
\hline \multirow{3}{*}{ Additional degree $(n=21)$} & Yes $=4(19 \%)$ \\
\hline & No $=17(81 \%)$ \\
\hline & Other degrees include: business (2); doctor of dentistry (2) \\
\hline \multirow{2}{*}{ Practiced as an LVN $(n=20)$} & Yes $=11(55 \%)$ \\
\hline & No $=9(45 \%)$ \\
\hline \multirow{3}{*}{ Currently employed (n = 23) } & Yes $=15(62.5 \%)$ \\
\hline & No $=8(37.5 \%)$ \\
\hline & $\begin{array}{l}\text { Areas of employment include: account manager (1); caregiver (5); dental office } \\
\text { worker (1); ECG tech (1); HR assistant (1); LVN, post-acute care (2); unknown (4) }\end{array}$ \\
\hline \multirow{2}{*}{ Country of birth $(n=23)$} & Born in Philippines = 20 (86\%) \\
\hline & Born in U.S.A. = $3(14 \%)$ \\
\hline \multirow{4}{*}{ Number of years in the U.S. $(n=23)$} & Mean $=5.3 \pm 6.1$ years \\
\hline & Median $=3.0$ years \\
\hline & Range $=1$ to 23 years \\
\hline & Mode $=3.0$ years \\
\hline
\end{tabular}

\subsection{Statistical findings}

The study found that PENSs' skills competency test scores greatly improved by the end of the 10 -week medical-surgical course. A major, unexpected finding to this study was that the majority of PENS participants took longer than anticipated to complete each of the four stations during the pre-test. Because most of the PENSs took more than one hour to complete the four skills at each station, the entire pre-test procedure was not completed. Only two participants were able to rotate through all four stations in the allotted time. Five of the participants could only complete 2 stations and the other 16 completed three stations; therefore, it was not possible to compare pre- and post-test scores for all 16 skills using all 23 participants. While most of the PENSs had an incomplete set of pre-test scores, others received a zero on a particular skill for not knowing how to begin and re- quiring full direction from the test monitor. On the pretest, the score of zero occurred most frequently with the PICC dressing change (13 out of 19). There were no zero scores assigned for the pre-test skills of urinary catheter insertion, intravenous catheter insertion, wet to moist dressing change, set up of primary intravenous fluid infusion, tracheostomy suctioning, chest drain set up, and vitamin $\mathrm{K}$ injection. The pre-test score of 100 was found for Salem sump insertion, PICC blood draw, and heparin injection.

The nursing skills competency test scores of the PENSs showed improvement in the mean average for all 16 skills, with statistically significant improvement in 14 of the 16 skills (see Table 2). Test scores ranged from zero to 100 for both the pre-test and post-test; however, there were 41 scores of zero out of 273 completed skills tests (15\%) pre-test and 
only one score of zero out of 367 completed tests $(<1 \%)$ posttest. The wet to moist dressing change was the only skill that was not successfully performed in the post-test by one PENS participant.

Skills that showed the greatest competency improvement in mean test scores were associated with PICCs. There were 11 scores of zero in the PICC blood draw pre-test, and 13 scores of zero in the PICC dressing change pre-test. Thus, the median score for the pre-test was zero. The lowest post-test scores for these skills were 78 and 85 , respectively. While only eight PENSs scored over 90 on the pre-test for the PICC blood draw, 17 scored over 90 on the post-test. Similarly, six scored over 90 for the pre-test PICC dressing change, and 18 scored over 90 on the post-test.

The two skills that did not show a statistically significant improvement between pre- and post-tests were: 1) insertion of the Salem sump nasogastric tube, and 2) subcutaneous injection of heparin. While the mean scores improved, this was mainly due to a few very low scores in the pre-test, and overall, the ranges for the pre- and post-test scores were close. The pre- and post-test median scores were within one point of each other for both skills (93 and 92 median scores for the Salem sump nasogastric tube insertion; 98 and 97 median scores for the heparin injection).

Table 2. Comparison of Philippine-educated nurses' pre- \& post-course safe nursing skills-competency test scores nonparametric: related samples Wilcoxon signed rank test

\begin{tabular}{|c|c|c|c|c|c|c|}
\hline $\begin{array}{l}\text { Skill Test at } \\
\text { Time_1 and Time_2 }\end{array}$ & $\mathbf{N} *$ & $\begin{array}{l}\text { Mean Score } \\
\text { (Standard Deviation) }\end{array}$ & $\begin{array}{l}\text { Mean Difference in pre- and } \\
\text { post-scores (Standard Deviation) }\end{array}$ & $\begin{array}{l}\text { Range of } \\
\text { Scores (N) }\end{array}$ & $\begin{array}{l}\text { Median } \\
\text { Score }\end{array}$ & $\boldsymbol{P}$ \\
\hline NGT_1 & 18 & $58.61(48.23)$ & \multirow{2}{*}{$32.78(45.77)$} & $0-100(19)$ & 93 & \multirow{2}{*}{.064} \\
\hline NGT_2 & 18 & 91.39 (4.96) & & 83-99 (23) & 92 & \\
\hline PICC blood draw_1 & 18 & $38.33(49.46)$ & \multirow{2}{*}{$53.44(49.12)$} & 0-100 (19) & 0 & \multirow{2}{*}{.009} \\
\hline PICC blood draw_2 & 18 & $91.78(5.26)$ & & $78-100(23)$ & 94 & \\
\hline PICC change_1 & 18 & $27.28(45.26)$ & $67.22(43.34)$ & 0-99 (19) & 0 & .001 \\
\hline Heparin administration_1 & 18 & $76.39(42.05)$ & \multirow{2}{*}{$19.28(40.26)$} & 0-100 (19) & 98 & \multirow{2}{*}{.491} \\
\hline Heparin administration_2 & 18 & $95.67(4.94)$ & & 83-100 (98) & 97 & \\
\hline Urinary cath placement_1 & 14 & 74.82 (9.83) & \multirow{2}{*}{19.75 (8.23) } & $60-90(15)$ & 79 & \multirow{2}{*}{.001} \\
\hline Urinary cath placement_2 & 14 & $94.57(4.05)$ & & $86-100(23)$ & 94 & \\
\hline IV start_1 & 14 & $65.00(17.94)$ & \multirow{2}{*}{30.29 (17.37) } & $32-96(15)$ & 72 & \multirow{2}{*}{.001} \\
\hline IV start_2 & 14 & 95.29 (3.79) & & $85-100(23)$ & 95 & \\
\hline Enteral feeding_2 & 14 & $92.21(7.15)$ & 38.21 (20.89) & $77-100(23)$ & 94 & .001 \\
\hline Insulin administration_1 & 14 & $66.79(24.40)$ & \multirow{2}{*}{$28.79(23.46)$} & $0-97(15)$ & 69 & \multirow{2}{*}{.001} \\
\hline Insulin administration_2 & 14 & 95.57 (2.95) & & $89-100$ (23) & 95 & \\
\hline Dressing change_1 & 16 & $75.63(15.68)$ & \multirow{2}{*}{$10.94(25.31)$} & 48-97 (17) & 78 & \multirow{2}{*}{.020} \\
\hline Dressing change_2 & 16 & $86.56(23.44)$ & & 0-99 (23) & 92 & \\
\hline Intravenous push_1 & 16 & $80.19(11.11)$ & \multirow{2}{*}{$10.56(14.51)$} & 58-98 (17) & 79 & \multirow{2}{*}{.010} \\
\hline Intravenous push_2 & 16 & $90.75(6.21)$ & & $80-98(22)$ & 91 & \\
\hline Primary infusion_1 & 17 & $78.18(13.20)$ & \multirow{2}{*}{$15.65(14.07)$} & $51-93(17)$ & 83 & \multirow{2}{*}{$<.001$} \\
\hline Primary infusion_2 & 17 & $93.82(3.36)$ & & $86-100(23)$ & 94 & \\
\hline Secondary infusion_1 & 17 & 70.47 (28.29) & \multirow{2}{*}{$24.88(26.62)$} & 0-98 (17) & 78 & \multirow{2}{*}{$<.001$} \\
\hline Secondary infusion_2 & 17 & 95.35 (3.53) & & $88-100$ (23) & 95 & \\
\hline Trach suctioning_1 & 16 & $67.19(11.21)$ & \multirow{2}{*}{$28.13(12.44)$} & $47-86(17)$ & 67 & \multirow{2}{*}{$<.001$} \\
\hline Trach suctioning_2 & 16 & $95.31(3.11)$ & & 89-100 (23) & 96 & \\
\hline Chest drain set up_1 & 16 & $95.06(20.63)$ & $31.81(20.16)$ & 25-95 (17) & 70 & .001 \\
\hline Blood set up _1 & 17 & 59.35 (27.75) & \multirow{2}{*}{$35.47(27.81)$} & 0-91 (18) & 67 & $<.001$ \\
\hline Blood set up_2 & 17 & $94.82(1.90)$ & & $92-98$ (23) & 95 & \\
\hline Vitamin K injection_1 & 16 & $78.50(10.68)$ & $20.06(11.48)$ & 63-99 (17) & 76 & $<.001$ \\
\hline Vitamin K injection_2 & 16 & $98.56(1.83)$ & & $95-100(23)$ & 99 & \\
\hline
\end{tabular}

*Number of students who took both the pre- and post- tests, i.e., number of comparisons.

An analysis of variance (ANOVA) was used to compare means according to demographic data (see Table 3). Overall, the demographic situation of the PENSs had little influence on skill competency. For example, age, gender, and birth- place did not seem to play a part in ability to perform the skill. Years living in the United States, LVN status, and current employment, however, did influence pre-test skill competency. PENS participants who had been living in the US for less 
than three years had higher scores than those who had lived in the US longer. Likewise, PENS participants with LVN licenses and those who were employed performed higher in pre-testing. Post-test scores showed no difference indicating that the medical-surgical course brought the students to a similar level of competency.

Table 3. Analysis of skills competency test scores with ANOVA

\begin{tabular}{|c|c|c|}
\hline Characteristic & Overall p-value (alpha set at .05) & Explanation of differences in pre- and post- test scores for 16 skills \\
\hline $\begin{array}{l}\text { Age equal to or } \\
\text { greater than } 30\end{array}$ & $p>.05$, not significant & $\begin{array}{l}\text { No statistical difference in any of the test scores for the } 16 \text { skills between } \\
\text { those }<30 \text { and } \geq 30 \text { years. }\end{array}$ \\
\hline $\begin{array}{l}\text { Gender-male or } \\
\text { female }\end{array}$ & $p>.05$, not significant & $\begin{array}{l}\text { No statistical difference in any of the test scores for the } 16 \text { skills between } \\
\text { males and females. }\end{array}$ \\
\hline $\begin{array}{l}\text { Birthplace-U.S. } \\
\text { or Philippines }\end{array}$ & $p>.05$, not significant & $\begin{array}{l}\text { No statistical difference in any of the test scores for the } 16 \text { skills between } \\
\text { those born in the U.S. and those born in the Philippines. }\end{array}$ \\
\hline $\begin{array}{l}\text { Greater than } 3 \\
\text { years in U.S. }\end{array}$ & $\begin{array}{l}p>.05, \text { not significant, except for } \\
2 \text { skills (see explanation) }\end{array}$ & $\begin{array}{l}\text { For PICC blood draw, students who were in the U.S. } \leq 3 \text { years had } \\
\text { significantly higher scores for the pre-test (mean }=74) \text { than those who had } \\
\text { been in the U.S. }>3 \text { years (mean }=18), p=.010 \text {. While both groups } \\
\text { improved their mean scores to } 92 \text { and } 93 \text { respectively, the mean difference } \\
\text { between pre- and post-test scores was greater for students in the U.S. }>3 \\
\text { years }(p=.024) \text {. } \\
\text { For PICC dressing change, students who were in the U.S. } \leq 3 \text { years had } \\
\text { significantly higher scores for the pre-test (mean }=61) \text { than those who had } \\
\text { been in the U.S. }>3 \text { years (mean }=9), p=.012 . \text { While both groups } \\
\text { improved their mean scores to } 94, \text { the mean difference between pre- and } \\
\text { post-test scores was greater for students in the U.S. }>3 \text { years }(p=.022) \text {. }\end{array}$ \\
\hline $\begin{array}{l}\text { Greater than } 5 \\
\text { years since } \\
\text { graduation }\end{array}$ & $p>.05$, not significant & $\begin{array}{l}\text { No statistical difference in any of the test scores for the } 16 \text { skills between } \\
\text { those who graduated } \leq 5 \text { and those who graduated }>\text { than } 5 \text { years ago. }\end{array}$ \\
\hline $\begin{array}{l}\text { LVN at time of } \\
\text { course }\end{array}$ & $\begin{array}{l}p>.05, \text { not significant, except for } \\
1 \text { skills (see explanation) }\end{array}$ & $\begin{array}{l}\text { Regarding blood administration, LVNs had significantly higher scores } \\
(\text { mean }=73) \text { for the pre-test than non-LVNs }(\text { mean }=35), p=.002 . \text { While } \\
\text { both groups improved their mean scores to } 95 \text {, the mean difference } \\
\text { between pre- and post-test scores was greater for non-LVNs }(p<.001) \text {. }\end{array}$ \\
\hline $\begin{array}{l}\text { Employed } \\
\text { during the } \\
\text { course }\end{array}$ & $\begin{array}{l}p>.05, \text { not significant, except for } \\
2 \text { skills (see explanation) }\end{array}$ & $\begin{array}{l}\text { Regarding heparin administration, students who were employed had } \\
\text { significantly higher scores (mean }=91) \text { than those who were not employed } \\
(\text { mean }=54), p=.036 \text {. While both groups improved their mean scores to } 96 \\
\text { and } 95 \text { respectively, the mean difference between pre- and post-test scores } \\
\text { was greater for students who were not employed }(p=.039) \text {. } \\
\text { Regarding blood products administration, students who were employed } \\
\text { had significantly higher scores (mean }=71) \text { than those who were not } \\
\text { employed (mean }=7), p=.001 \text {. While both groups improved their mean } \\
\text { scores to } 95 \text {, the mean difference between pre- and post-test scores was } \\
\text { greater for students who were not employed }(p<.001) \text {. }\end{array}$ \\
\hline
\end{tabular}

\section{Discussion}

All skills competency test scores increased significantly except for the Salem sump nasogastric tube insertion and the heparin injection. Scores for these two skills increased but were not statistically significant. The Salem sump nasogastric tube insertion and the heparin injections began with high pre-test scores, thus limiting the opportunity for statistical significance. Also these two skills occurred at the same station with the same test monitor. Possibly the test monitor was not as consistent in scoring as monitors at the other sta- tions. It is also possible that PENSs had more opportunity to practice nasogastric tube insertion, drawing medication from a vial, and injecting subcutaneously while in their international program. Interestingly, the subcutaneous insulin injection yielded lower scores possibly due to the increased complexity in drawing up the medication. For example, the insulin injection required checking a record for blood sugar value, drawing up two injections, and verifying both with another RN.

The PENSs might have scored low on certain skills prior to 
the course for two reasons: lack of practice over several years and lack of opportunity to perform the skill in their Philippine nursing program. While most of the participants had attained their BSN in the Philippines in the current decade, three participants had graduated in 2005, 2007 respectively. Many PENSs were currently employed in a caregiver role such as a nursing assistant or LVN for a home health or skilled nursing facility. It is likely that they had opportunity to perform some of the acute care skills such as heparin injection in their current work settings. During pretesting, some participants indicated that they had little or no chance to perform certain skills such as PICC dressing changes during the course of their program in the Philippines and that they had never experienced certain pieces of equipment such as a chest drain or infusion pump.

The test monitors consistently observed and made comments on the scoring records. The most common mistakes made by the PENS participants were 1) caps replaced onto used needles instead of placing into readily available sharps containers, and 2) break in sterile technique occurred when the PENSs would touch non-sterile items after donning sterile gloves. Interestingly, all PENS in the study correctly donned sterile gloves.

ANOVA revealed an unexpected finding that participants who had lived in the US less than 3 years had significantly higher scores for PICC dressing change and blood draw. Possibly, number of years living in the US can be associated with number of years since graduation. Those living in the US for a longer time might not have had exposure to care of the PICC since graduating years ago. Work history was more likely to determine skill performance with those working as LVNs having higher scores for heparin injection and set up of blood transfusion.

Previous studies have reported that international nurses have had the most struggle with technology, providing total care to patients, communication, and working with complex healthcare teams. ${ }^{[16,17]}$ The skills stations in this study allowed each PENS to practice integrating each of these components. On post-testing, specific skill competency test scores increased and also the flow of the station improved as the PENSs were able to communicate with the patient and family and prioritize care.

\section{Limitations}

The primary limitation of this study was that it involved one small group of PENSs at one university. Therefore, the findings cannot be generalized to all IENs who immigrate to the US. The skills competency testing scoring rubrics have been used consistently for multiple tests over a 2-year period and

Published by Sciedu Press have yielded consistent scores among various raters, however inter-rater reliability had not been performed prior to this study. The test monitors did undergo similar orientation and had served as test monitors in the past; yet, inter-rater reliability was not established. In addition, the results of this study would be made stronger by using the same test monitors over the two consecutive pre-test and post-test days.

Another major limitation to this study was the potential influence of three separate variables on score improvement. It was not possible with the study design to distinguish whether scores improved because of time spent in lecture, time spent in the clinical setting, or time spent with practice in the Clinical Simulation Center. However, the simulation setting allowed for control over practicing the specific skills, which cannot consistently be arranged in a clinical environment.

\section{SUGgESTIONS FOR FURTHER RESEARCH}

Very little has been published about nursing program curricula outside of the US despite the prevalence of nurses who receive their education abroad. More research is needed to understand the differences in nursing education programs worldwide, particularly in the Philippines, which has the highest rate of emigration. A qualitative study to learn about both didactic and clinical experiences in nursing programs outside of the US would be of great interest. Finally, it would be valuable to repeat this study with consistent test monitors, established inter-rater reliability, a larger sample size, and participants from countries other than the Philippines.

\section{Conclusions}

Given the anticipated need for RNs in the upcoming decades and the propensity of IENs, particularly those from the Philippines, to practice in the US, increasing an understanding of the differences in educational programs is essential. Nurses educated in the Philippines seeking to attain RN licensure in the state of California could benefit from additional education to facilitate assimilation to US culture. This additional education could occur through taking courses in accredited schools of nursing and through transition programs provided by employers as stated throughout the literature. The focus of this study was with psychomotor skill practice, but additional education in communication, US culture, and technology would be beneficial to those who immigrate to the US.

With 24 hours of practice in the Clinical Simulation Center and completion of theory and acute care clinical hours, PENSs demonstrated significant improvement in competency of commonly-performed adult medical surgical skills. Based on the findings in this study, PENSs could benefit from skill practice prior to assuming care of acutely ill adults in the 
US healthcare system. In addition, those organizations that hire PENSs may want to consider skill competency testing to validate skill competency to ensure patient safety. This study made a start at discovering the baseline abilities of a small group of PENs in performing 16 common medical-surgical skills.

\section{Conflicts OF InTEREST Disclosure}

The authors declare that there is no conflict of interest statement.

\section{REFERENCES}

[1] American Association of Colleges of Nursing. Nursing shortage. 2015. Available from: http://www . aacn.nche.edu/media-rel ations/fact-sheets/nursing-shortage

[2] United States Department of Labor. Bureau of labor statistics. 2015 Available from: http://www.bls.gov/news.release/ecopro. t08.htm

[3] Spetz J, Lee PR. Forecasts of the registered nurse workforce in California. Conducted for the California Board of Registered Nursing. University of California San Francisco; 2010.

[4] Spetz J, Gates M, Jones CB. Internationally educated nurses in the United States: Their origins and roles. Nursing Outlook. 2013; 62(1): 8-15. PMid:23809601 http://dx.doi.org/10.1016/j.outlo ok. 2013.05.001

[5] Pittman P, Folsom A, Bass E, et al. U.S. -based nurse recruitment: Structures and practices of a burgeoning industry. 2007. Available from: http://www.intlnursemigration.org/asset s/pdfs/Report-on-Year-I.pdf

[6] Xu Y, Zaikina-Montgomery H, Shen J. Characteristics of internationally educated nurses in the United States: An update from the 2004 National Sample Survey of Registered Nurses. Nursing Economics. 2010; 28(1).

[7] Adeniran R, Rich V, Gonzalez R, et al. Transitioning internationally educated nurses for success: A model program. The Online Journal of Issue in Nursing. 2008; 13(2).

[8] Zenaida S. Transcultural care values and nursing practices of Philippine-American nurses. Journal of Transcultural Nursing. 1992; 3(2): 28-37. http://dx.doi .org/10.1177/104365969200300 205

[9] $\mathrm{Xu} \mathrm{Y.} \mathrm{A} \mathrm{comparison} \mathrm{of} \mathrm{regulatory} \mathrm{standards} \mathrm{for} \mathrm{initial} \mathrm{registra-}$ tion/licensure of internationally educated nurses in the United Kingdom, Australia, Canada, and the United States. Journal of Nursing Regulation. 2011. http://dx.doi.org/10.1016/S2155-8 256 (15) 30270-2

[10] Yeates N. The globalization of nurse migration. Policy issues and responses. International Labour Review. 2010; 149(4). http: //dx .doi.org/10.1111/j.1564-913X.2010.00096.x

[11] California Healthcare Almanac, California Nurses Facts and Figures. California Healthcare Foundation. 2010.

[12] Rodis R. Why are so many Filipino nurses in the US? New America Media - Asia. 2013. Available from: http: //newamericamedia.org/2013/05/telltale-signs-why-a re-there-so-many-filipino-nurses-in-the-us.php
[13] California Board of Registered Nursing. Title 16, California code of regulations. 2015. Available from: http://www.rn.ca.gov/regu lations/title16.shtml

[14] Philippine Nurses Association of America (PNAA), Inc. Position Statement: Concurrency of Clinical Experience of Philippine Nursing School Graduates. 2013. Available from: http://www .mypnaa.org/about-pnaa/position-stateme nts-and-press-releases7/491-position-statement-con currency-of-clinical-experience-of-philippine-nur sing-schools-graduates.html

[15] Jose M. Lived experiences of internationally educated nurses in hospitals in the United States of America. International Nursing Review. 2010; 57: 56-63.

[16] Yu X, Shen J, Bolstad AL, et al. Evaluation of an intervention on socio-cultural communication skills of international nurses. Nursing Economics. 2010; 28(6): 386-408.

[17] Li-Chen L. Filipina nurses' transition into the US hospital system. J Immigrant Minority Health. 2014; 16: 682-688. PMid:23417707 http://dx.doi.org/10.1007/s10903-013-9793-9

[18] Newton S, Pillay J, Higginbottom G. The migration and transitioning experiences of internationally educated nurses: A global perspective. Journal of Nursing Management. 2012; 20: 534-550. PMid:22591155 http://dx.doi.org/10.1111/j.1365-2834.2011.01222.x

[19] Vestal V, Kautz D. Responding to similarities and differences between Filipino and American nurses. Journal of Nursing Administration. 2009; 39(1): 8-10. PMid:19104280 http://dx.doi .org/10.10 97/NNA . Ob013e31818fe726

[20] Singh M, Sochan A. Voices of internationally educated nurses: Policy recommendations for credentialing. International Nursing Review. 2010; 58: 123-129. http://dx.doi.org/10.1111/j.1466-765 7.2009.00759.x

[21] Wheeler RM, Foster JW, Hepburn KW. The experiences of internationally educated nurses in the southeastern United States of America. International Nursing Review. 2013. PMid:23961803 http://dx.doi.org/10.1111/inr.12023

[22] World Health Statistics. 2014. Available from: http: //apps.who.int/iris/bitstream/10665/112738/1/9 789240692671_eng.pdf?ua=1

[23] SPSS statistical program, IBM Corp. Armonk, New York.

[24] Perry A, Potter P, Ostendorf W. Clinical Nursing Skills and Techniques, 8th ed. Elsevier, St Louis, MO. 2014.

[25] American Association of Colleges of Nursing. Quality and Safety Education for Nurses. 2015. Available from: http://www . aacn.n che.edu/qsen/home 